\title{
LITERATURA E MÚSICA EM (CON)FLUÊNCIA: O DIÁLOGO INTERMÍDIA NA LITERATURA JUVENIL
}

Luara Teixeira de Almeida (PUC-SP)

Diana Navas (PUC-SP)

Resumo: $O$ presente estudo objetiva, a partir da leitura das obras $O$ Rei (2015), de Luiz Tatit e Renato Moriconi, e Quaisqualigundum (2014), de Roger Cruz e Davi Calil, demonstrar o diálogo estabelecido entre literatura e música em obras contemporâneas preferencialmente endereçadas ao jovem leitor. Partindo dos estudos intermídias, propostos por Claüs Clüver, evidencia-se como a literatura juvenil contemporânea apresenta uma composição intermídia - em que linguagens como a da ilustração e do design fundem-se à linguagem verbal, expandindo os sentidos sugeridos pelo texto literário - para, na sequência, evidenciar o diálogo que estabelece com outras linguagens artísticas, tais como a da música. Por meio da leitura das obras selecionadas, demonstra-se como, por meio de diferentes estratégias compositivas, relações entre literatura e música são estabelecidas não apenas no plano do conteúdo, mas na própria arquitetura das narrativas em estudo graças às diferentes mídias de que são compostas e da leitura multimodal que delas se empreende. Palavras-chave: Literatura; Música; Mídia; Intermidialidade; Jovem leitor.

Abstract: The present study aims, considering the reading of $O R e i$ (2015), by Luiz Tatit and Renato Moriconi, and Quaisqualigundum (2014), by Roger Cruz and Davi Calil, demonstrate the dialogue established between literature and music in contemporary works preferably addressed to the young reader. Considering Claüs Clüver's intermedia studies, it is showed how contemporary youth literature presents an intermedia composition - in which languages such as illustration and design merge with verbal language, expanding the meanings suggested by the literary text - and how it dialogues with other artistic languages, such as music. By reading the selected works, it is demonstrated how, through different compositional strategies, relations between literature and music are established not only in the content level, but in the architecture of the narratives due to the different media of which they are composed and the multimodal reading that is required by them.

Keywords: Literature; Music; Media; Intermediality; Young reader. 


\section{MÍDIAS EM DIÁLOGO NA LITERATURA JUVENIL CONTEMPORÂNEA}

Em ampla e significativa expansão, a literatura juvenil brasileira tem, na contemporaneidade, investido na inovação temática e estrutural. Propondo não meramente a inserção de temas fraturantes, a produção preferencialmente endereçada ao jovem leitor tem incorporado, em sua arquitetura, diferentes "mídias", termo aqui compreendido a partir da perspectiva de Claus Clüver (2006), como suporte de diversas possibilidades de comunicação e representação, com códigos e convenções próprias. Em outras palavras, a literatura juvenil contemporânea, em consonância com nosso contexto histórico-cultural - no qual abundam as referências audiovisuais - tem absorvido, na construção narrativa, as linguagens da ilustração, do design, da música, do teatro, do cinema, da fotografia, rompendo com as tradicionais fronteiras entre as artes e apontando para uma composição marcada pela intermidialidade e confluência de linguagens.

Empregamos, aqui, portanto, o termo intermídia para nos referirmos a obras compostas a partir da relação entre dois ou mais textos semióticos distintos dentro de um mesmo suporte. Isto é, a textos que se apresentam como produtos de uma combinação, mescla ou aglutinação de diferentes 
linguagens. Ainda que este tipo de produção não seja uma novidade - sendo um fenômeno relativamente comum em todas as culturas e épocas - é fato que assistimos à sua proliferação e forte presença na literatura juvenil contemporânea, o que contribui para capturar a atenção e interesse do jovem leitor.

Estamos, assim, no âmbito da literatura, diante de produções que, mais do que amalgamarem os diferentes gêneros literários - como é o caso da prosa poética -, ou de possibilitarem a confluência da literatura com gêneros considerados não literários pela tradição - com e-mails e blogs, por exemplo, emergindo em meio ao texto literário - com obras que se revelam intermídias, isto é, construídas a partir da "fusão de processos e procedimentos midiáticos distintos" (CLÜVER, 2006, p.21). Obras nas quais os sentidos são construídos não mais meramente pelo texto literário, mas também pela linguagem da ilustração e do design. Produções que, conforme nos explicam Hassett \& Curwood, descentralizam a palavra escrita; diante das quais os leitores devem considerar a justaposição de múltiplos modos de comunicação, já que gráficos, imagens e outros modos "estendem, e frequentemente substituem, a palavra impressa como portadora principal de significado" (2009, p.271). 
No conjunto da produção literária juvenil brasileira, somase a esta composição intermidiática - em que os sentidos se permitem (re)construir a partir do diálogo simultâneo das diferentes linguagens que as constituem - a tendência ao diálogo com outras linguagens artísticas - entre elas a da música. Várias são as obras que estabelecem relações em termos conteudísticos - com letras de canções, sendo O rapaz que não era de Liverpool (2006, Edições SM), de Caio Riter, um claro exemplo deste tipo de produção. Nela, conforme sugere seu próprio título, estabelece-se o diálogo com as músicas dos Beatles, as quais, inclusive, intitulam os capítulos da narrativa, e com os quais, em um processo de mise-en-abyme, mantêm estreita relação temática.

Desafiadora, a literatura juvenil contemporânea, entretanto, não se limita a propor o diálogo entre literatura e música apenas no nível do enredo. Considerando que apresentam características próximas em muitos aspectos - a alternância na música indica o que denominamos de polifonia na literatura; ambas as linguagens podem ser acompanhadas conforme seu andamento, ritmo e articulações; uma letra de canção pode, muitas vezes, ser considerada poesia, enquanto que muitos poemas possuem melodias e métricas possíveis de musicalização - observa-se, 
em variadas produções, o incorporar da linguagem da música na estrutura da obra literária. Dito de outra maneira, em uma espécie de movimento antropofágico, a obra literária assimila, não apenas em termos temáticos, mas em sua arquitetura, elementos da linguagem musical, construindo um texto híbrido.

Trata-se de um tipo de produção que demanda, portanto, uma leitura em que não haja a sobreposição entre as linguagens, ou seja, não se vise a valorização de uma determinada mídia em detrimento de outra. Ao contrário, solicita a interlocução entre elas, haja vista que diversos procedimentos convivem, em dado objeto artístico - no caso, o livro - possibilitando combinações de processos que resultam na hibridização de campos artísticos cada vez mais interpenetráveis e contaminados entre si. Um tipo de produção que, justamente em razão de sua complexidade, atrai a atenção e o interesse do jovem leitor, que, à semelhança do que evidencia em seu cotidiano, encontra na obra de arte linguagens plurais e que dele demandam uma leitura sinérgica.

É um olhar capaz de minimizar as fronteiras entre as artes e diferentes linguagens que constituem o livro juvenil contemporâneo e a proposição de uma leitura multimodal que objetivamos no presente estudo. Almejamos, a partir 
da leitura de duas obras preferencialmente endereçadas ao jovem leitor - O Rei (2015), de Luiz Tatit e Renato Moriconi, e Quaisqualigundum (2014), de Roger Cruz e Davi Calil, evidenciar o diálogo estabelecido entre literatura e música, a partir de diferentes estratégias compositivas.

\section{O REI, DE LUIZ TATIT E RENATO MORICONI}

A obra O Rei (2015), da Editora Jujuba, constrói um diálogo entre literatura e música já em sua concepção, haja vista que traz, como texto verbal, a letra de uma canção do músico Luiz Tatit, à qual soma-se o texto visual do artista plástico Renato Moriconi. Se, a princípio, poderíamos conceber esse produto como uma tradução intersemiótica, ou seja, como um texto em que se transporta uma mídia primeira - a música - para uma segunda - o livro ilustrado -, sua leitura demonstranos que esta seria uma concepção equivocada. Isso porque, uma leitura mais atenta permite-nos observar que não se trata de uma simples "adaptação" de um suporte a outro, mas, conforme demonstraremos, assiste-se à expansão do sentido da letra da canção nesse outro suporte, de forma intermidiática.

A leitura sinérgica de $O$ Rei permite-nos constatar que o diálogo com a música estabelece-se por meio das três linguagens que a constituem: no literário, uma vez que o texto que veicula é uma canção; na narrativa visual, por meio 
da grande quantidade de referências e elementos musicais, e também no projeto gráfico, que se utiliza do repertório leitor para dar início a esse diálogo entre as mídias.

A obra possui o formato quadrado, do tamanho dos discos de vinis e, para acessar o livro em si, é preciso retirálo da luva, tal qual faríamos com um LP. O movimento de deslocar o objeto de sua proteção permite-nos o acesso ao seu título, no qual figura o termo "rei", conduzindo o leitor, desta forma, a identificar este como sendo o personagem principal da obra. Esse rei, no entanto, conforme realizamos a leitura do texto verbal, não é por ele definido, revelado, permitindo-se somente ser identificado como o Sol, o astro rei, por meio da linguagem da ilustração. Esta descoberta, no entanto, só nos é possível, inicialmente, em virtude do projeto gráfico da obra: apenas quando, participando de forma ativa, o leitor manuseia o livro e empreende o virar da página, é que promove o movimento de nascer do Sol e, desta forma, dá início à narrativa.

A leitura atenta, no entanto, evidencia-se que o elemento sol não se limita a designar o "astro rei", mas que aponta, também, para o diálogo com a música, visto, como sabemos, "sol" tratar-se de uma nota musical. Temos, assim, o rei do texto verbal, que é representado visualmente como astro rei - o Sol - que, por seu turno, é uma nota musical - e 
várias são as referências visuais aos elementos musicais apontando portanto para o diálogo com entre literatura e música a partir das diferentes linguagens que compõem esta obra literária.

Ao abrirmos o livro, deparamo-nos com uma página dupla amarela, iluminada, indicando a presença desse Sol que nasceu. A página seguinte, como vemos na Figura 1, apresenta uma partitura tomando toda a extensão do livro, com representações de notas musicais. Entre elas, uma grande mancha amarela, tomando o lugar de uma nota, remete-nos novamente ao Rei Sol.

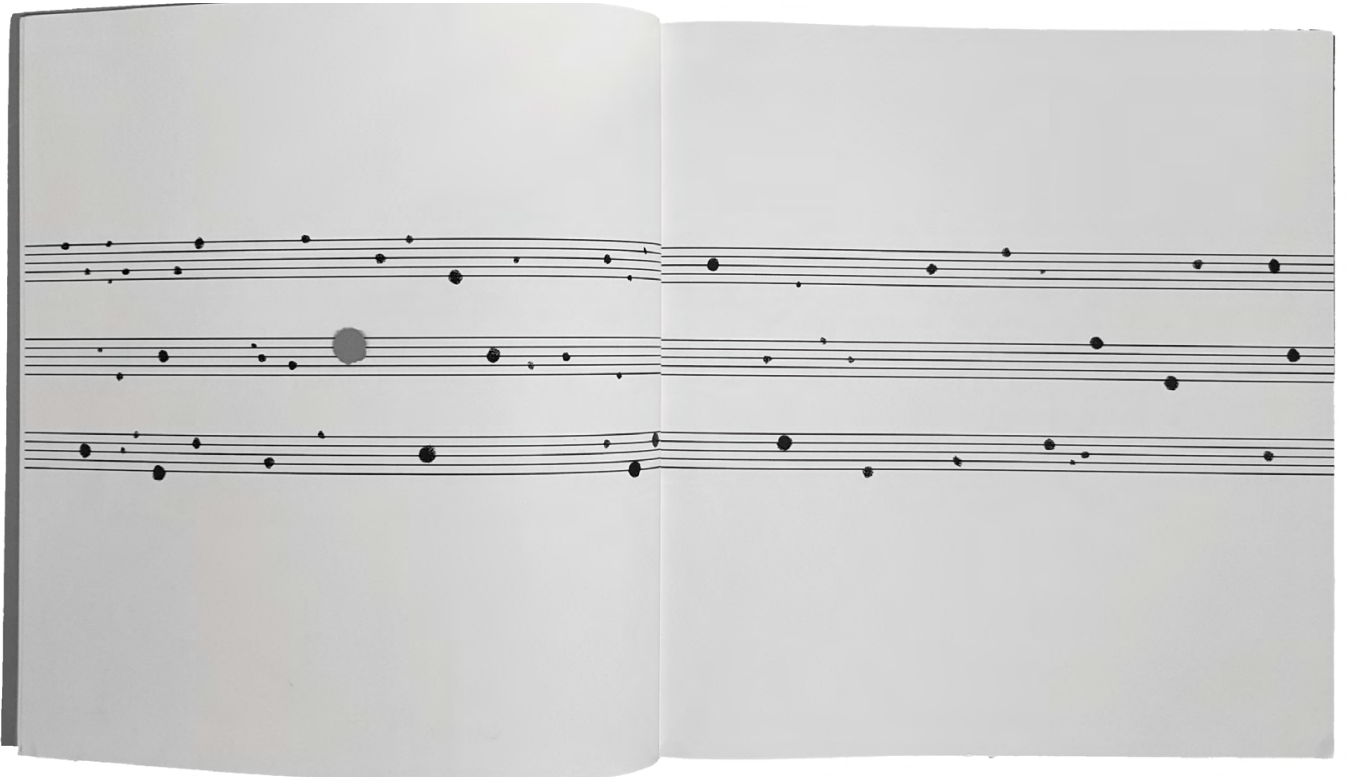


$\mathrm{Na}$ dupla consecutiva, encontramos o vazio tomando conta de quase todo o espaço, exceto por uma clave de sol que é posta no centro da página direita. A clave, na música, tem a função de indicar como ler as notas e aparece sempre no início das partituras. A função dela, nesse livro, portanto, parece ser a de nos indicar que se dará início à narrativa verbal, e sendo ela a clave de sol, que leremos a história desse Rei Sol. Como pode ser notado, a escolha do símbolo musical presente nesse momento da narrativa remete-nos à sintaxe da música, a qual é incorporada à linguagem do livro.

O texto verbal é a letra, na íntegra, da canção "O Rei", de Luiz Tatit, a qual faz parte do álbum Felicidade, de 1997. A letra encontra-se diagramada na forma de versos, espalhados ao longo das páginas, e suas manchas gráficas ganham concretude, sugerindo a materialização daquilo que está a ser narrado. Temos, como exemplo, o trecho "todo dia ele desce de tarde; vem ver os seus súditos; se está tudo em ordem"; nesse momento, a mancha tipográfica se apresenta em uma leitura diagonal descendente, tal qual o movimento do Sol ao vir ver seus súditos, de modo que o espaço em branco da página torna-se mais um elemento do fazer literário, evidenciando, desta forma, a consonância entre a linguagem verbal e a do design. 
As ilustrações de Renato Moriconi são construídas com colagens, empregando muitas vezes, partituras musicais, como podemos observar na Figura 2. É possível ver nessa construção, novamente, o diálogo com a música, remetendonos à origem do texto verbal que no livro figura. É interessante também observar que a colagem é uma técnica que se assemelha à própria intermidialidade, um processo de composição que se utiliza de fragmentos e recortes de materiais diversos, de origens distintas, que se unem e são lidos de forma inseparáveis, em uma única imagem.

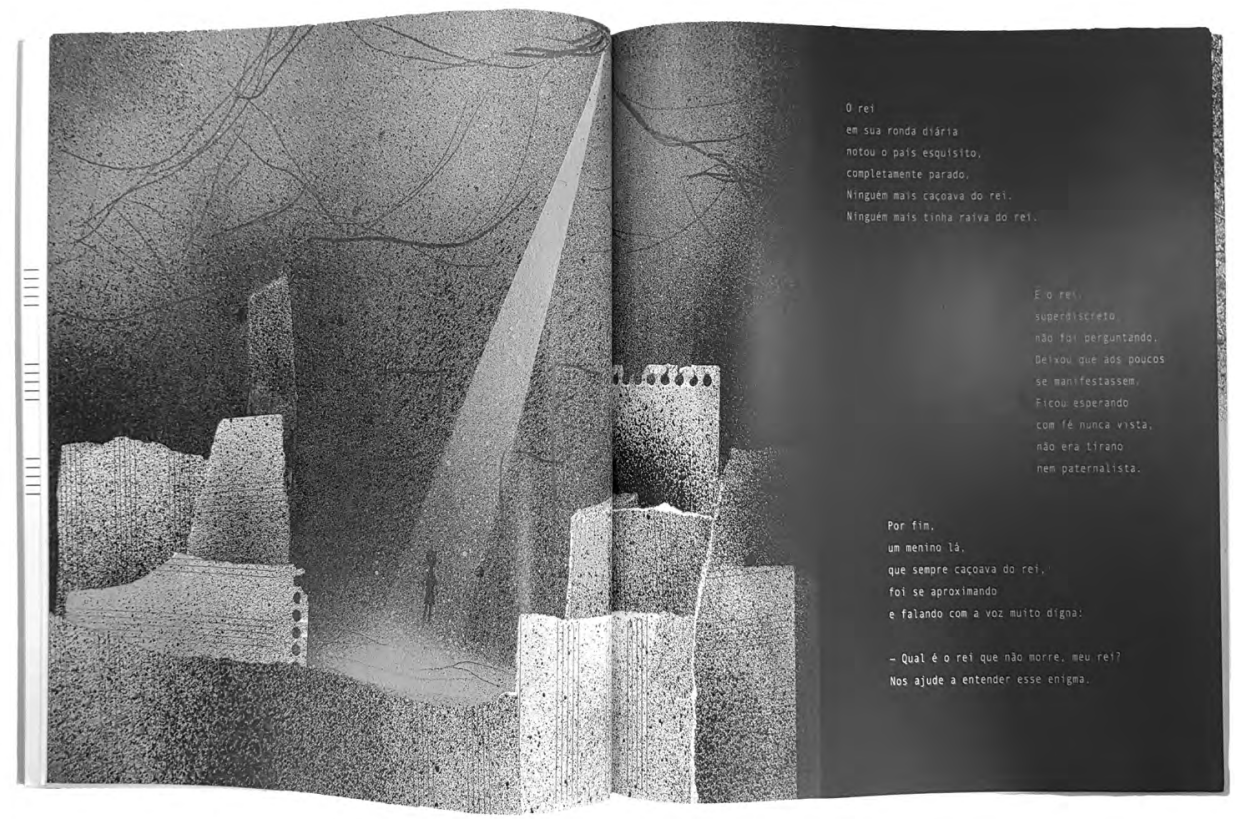

Figura 2 
A narrativa visual acompanha o tom destacado na música de Tatit. Isto é, no trecho em que a música se torna mais melancólica e a narrativa mais densa - "e eis que complicou; os poderes do mal devastaram o país, um feitiço cruel [...]" - visualmente temos a transição para páginas duplas que se utilizam muito de cores escuras, a preta principalmente. Momentos caóticos da música são representados com ilustrações e manchas de textos igualmente confusas, ao passo que momentos alegres e divertidos da canção, como a resolução da narrativa, trazem páginas muito claras, com espaços em branco e predominância do amarelo do Sol.

Como pode ser então observado, essa obra, que é composta por mídias diferentes já por sua condição de livro ilustrado - une texto verbal, visual e projeto gráfico adiciona uma nova camada de diálogo com diferentes meios ao incorporar, nessas três linguagens, aspectos da linguagem da música. Nota-se, entretanto, em sua construção, que o diálogo com a música é estabelecido, principalmente, por meio do projeto gráfico e da narrativa visual, e não meramente pelo texto verbal que veicula constituir-se como letra de canção. 


\section{QUAISQUALIGUNDUM (2014), DE ROGER CRUZ E DAVI CALIL}

O livro em quadrinhos Quaisqualigundum, publicado pelo selo Dead Hamster, em 2014, também tece um profícuo diálogo com a música. O álbum é composto por quatro histórias, apenas aparentemente independentes, que nos remetem a canções de Adoniran Barbosa: "Maloca" (Saudosa Maloca), "A Saga do Ernesto" (Samba do Arnesto), "Mané e Marinez" (Apaga o fogo, Mané) e "Cipolla e Bracholas" (Samba no Bexiga). A narrativa, no entanto, não é uma mera adaptação das músicas para uma nova mídia.

Roger Cruz, roteirista, se utiliza dos universos criados nas canções para desenvolver novas histórias, que se passam antes, durante ou depois do que nos foi apresentado por Adoniran em suas canções, extrapolando as construções espaço-temporais das músicas. No capítulo “Maloca” (2014, p.6), a título de exemplo, nos é contada a forma como os personagens "eu, Matogrosso e o Joca", figuras da canção Saudosa Maloca, se conheceram e foram morar naquele edifício.

Essa forma de reinterpretação das músicas, que estabelece um claro diálogo com as músicas de Adoniran, agrega, em nosso ponto de vista, valor para ambas as 
mídias. Isso porque, para a história em quadrinhos, ter como base clássicos da música popular brasileira atribuiIhe credibilidade e pertencimento a uma tradição; para as músicas de Adoniran, lançadas nos anos 60, possibilita reviver da obra, a sua perpetuação. Esse diálogo intermídias, portanto, se faz acertado no sentido de ampliar os sentidos para ambas as linguagens.

Mais do que trazerem, tematicamente, referências ao conteúdo das canções de Adoniran, as histórias presentes em Quaisqualigundum incorporam aspectos estruturais da linguagem musical desse intérprete. Exemplo disso é que a linguagem utilizada nas canções - uma linguagem popular e gramaticalmente incorreta, de que é claro exemplo a música Saudosa Maloca - é incorporada nas histórias gráficas. A título de exemplo, em "Maloca", a história correspondente à letra da canção no livro, faz-se uso dessa estratégia quando o personagem diz: "tá intregano jornar di porta im porta, mermo com as perna doeno" (CRUZ; CALIL, 2014, p.14), reproduzindo a fala paulistana popular, a qual claramente se evidencia na canção de Adoniram, e apontando para as diferenças sociais e os problemas que surgem diante delas.

Outra estratégia empregada, em especial por meio da linguagem verbal, é a transtextualidade, o estabelecimento 
de relações intertextos, isto é, "tudo que o coloca em relação, manifesta ou secreta, com outros textos" (GENETTE, 1982 , p.7). Conforme pode ser observado, o próprio título da obra, considerado um paratexto, traz a expressão "quaisqualigundum", a qual já ressoa aos ouvintes de Adoniran como parte da introdução da canção Saudosa Maloca, indicando, portanto, o teor do enredo que se seguirá.

A intertextualidade com outras canções de Adoniran Barbosa, que não estão presentes diretamente nas histórias, também se faz notar. Em "Cipolla e Bracholas" (2014, p.66), por exemplo, o samba que o grupo está tocando durante toda a narrativa é a canção Tiro ao Álvaro e, em "Ernesto" (2014, p.32), vemos um personagem cantarolar Trem das Onze. Esses diálogos intertextuais não são trazidos na forma de citações diretas; ao contrário, as canções de Adoniran surgem nas entrelinhas, em meio ao cantarolar dos personagens, como algo espontâneo de seu cotidiano, estando os trechos das letras alternados com um "lálaiá" (2014, p.46), muito comum no ritmo do samba. Essas músicas são introduzidas no texto sem qualquer menção de fonte, constituindo-se como alusões e, portanto, um gatilho para um possível aprofundamento do jovem leitor, que é incitado a buscar mais conhecimento em torno da 
obra em outros meios - como escutar as músicas originais de Adoniran. Destarte, trechos das letras das canções em meio à construção narrativa não são utilizadas apenas para preencher vazios, mas para construir e ampliar significados, remeter à obra do compositor aqueles que não a conhecem, e promover o reconhecimento por parte daqueles que já são ouvintes do sambista.

Outras relações intertextuais com as músicas de Adoniran são apresentadas de forma mais sutil, mas que os leitores com uma bagagem das canções são capazes de acompanhar. Em "Maloca" (2014, p.8), por exemplo, o narrador-personagem explica "eu ia tenta guentá a noite com o meu cubertô quano arguém tentô tirá ele di mim; mas eu num queria morre di frio naquela noite", fazendo referência à música Saudosa Maloca, cuja letra diz: "Só se conformemos quando o Joca falou 'Deus dá o frio conforme o cobertor'”. É possível, também, encontrar citações diretas não referenciadas, como é o caso da última cena desse mesmo capítulo, apresentada pela Figura 3, em que o personagem, conversando com o outro, afirma: "si u sinhô num tá lembrado... dá licença di conta..."; sabe-se que essa é a primeira frase do samba em que Adoniran conta a história daquele "palacete assobradado". Essa referência, para os conhecedores do cantor, traz junto 
a melodia da canção, que mentalmente é cantada ao se empreender a leitura sinérgica de texto, imagem e projeto gráfico.

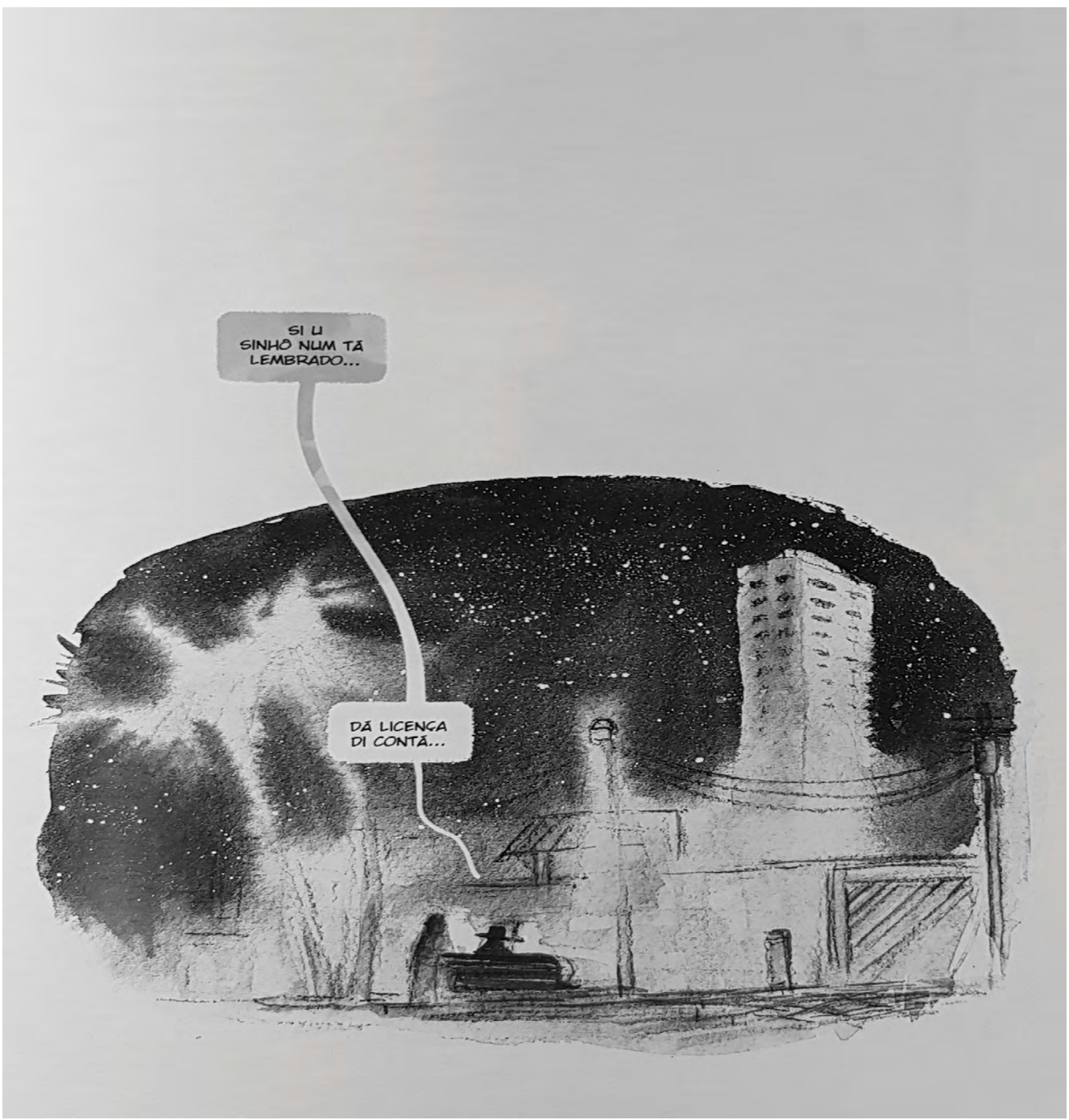

Figura 3 
Apesar de a construção desta obra literária, como vimos, partir da obra musical de Adoniran Barbosa e, portanto, constituir-se como um texto que deriva de um outro - o que é denominado de hipertextualidade por Genette (1982), é importante salientar que ela se sustenta como obra individual, criando suas próprias intertextualidades. Nela, as quatro histórias em quadrinho apresentadas conversam entre si e são apresentadas de forma não linear. "Ernesto" (2014, p.32), narrativa derivada da canção Samba do Arnesto, traz-nos, rapidamente, um personagem com o olho roxo de uma briga. Em "Cipolla e Bracholas" (2014, p.66), história inspirada na canção Samba no Bexiga, acompanhamos esse personagem e como ele se envolveu em uma briga para "ganhar" o olho roxo. Além disso, as narrativas gráficas expandem o conteúdo das letras das canções, oferecendo "explicações" para situações nelas expressas. Exemplo disso é que se a letra de Samba do Arnesto diz: "O Arnesto nos convidô prum samba, ele mora no Brás; Nóis fumo e não encontremos ninguém"; em "Ernesto" (2014, p.32), a narrativa gráfica nos conta o motivo de Arnesto não estar onde combinou com seus convidados: seu envolvimento em uma briga por dinheiro após um jogo de dominó. Em “Cipolla e Bracholas" (2014, p.66), vemos um grupo de samba que diz:

- O Ernesto convidou a gente pra tocar na festa. Ele já chegou? 
- Ainda não. Mas isso é bem do Ernesto.

Daqui a pouco ele aparece com uma desculpa esfarrapada. (CRUZ; CALIL, 2014, p.68)

Percebemos também que, ainda que estejam apresentadas em capítulos diferentes, contadas a partir de diferentes pontos de vista e envolvam outros personagens e tempo, trata-se de narrativas apenas aparentemente independentes, visto que estabelecem conexões. Exemplo disso é que, em "Ernesto", (2014, p.32), quando acompanhamos Ernesto fugindo de três homens e, no momento em que é encurralado em um beco, um personagem o ajuda a se livrar, e ele diz: "três contra um é covardia" (CRUZ; CALIL, 2014, p.44); tal personagem muito se assemelha visualmente com Matogrosso, apresentado em "Maloca" (2014, p.8), como um dos moradores da casa derrubada na canção Saudosa Maloca, descrito como "um toro dos brabos quano vê injustiça" (2014, p.16).

A técnica de ilustração que Davi Calil utilizou nessa obra mistura guache, acrílica e aquarela. O uso de técnicas nãodigitais conversa muito bem com a música de Adoniran, que também é tradicional, periférica, além de trazer movimento e dinamismo, tal qual um samba. $O$ estilo de traço e cores trabalhadas em cada capítulo são levemente distintos, traduzindo os sentimentos e melodias de cada uma das músicas. "Cipolla e Bracholas" (2014, p.66), por 
exemplo, capítulo que se refere à música Samba no Bixiga, é composta por cores alegres e vivas pois, ainda que trate de uma briga em um bar, é uma canção muito bem-humorada e descontraída. Por sua vez, a canção Apaga o fogo, Mané é construída com teor de samba melancólico e esse caráter é transmitido, em termos visuais, por meio de tons escuros e muitas cenas de chuva no capítulo "Mané e Marinez" (p.48), como podemos observar na Figura 4.

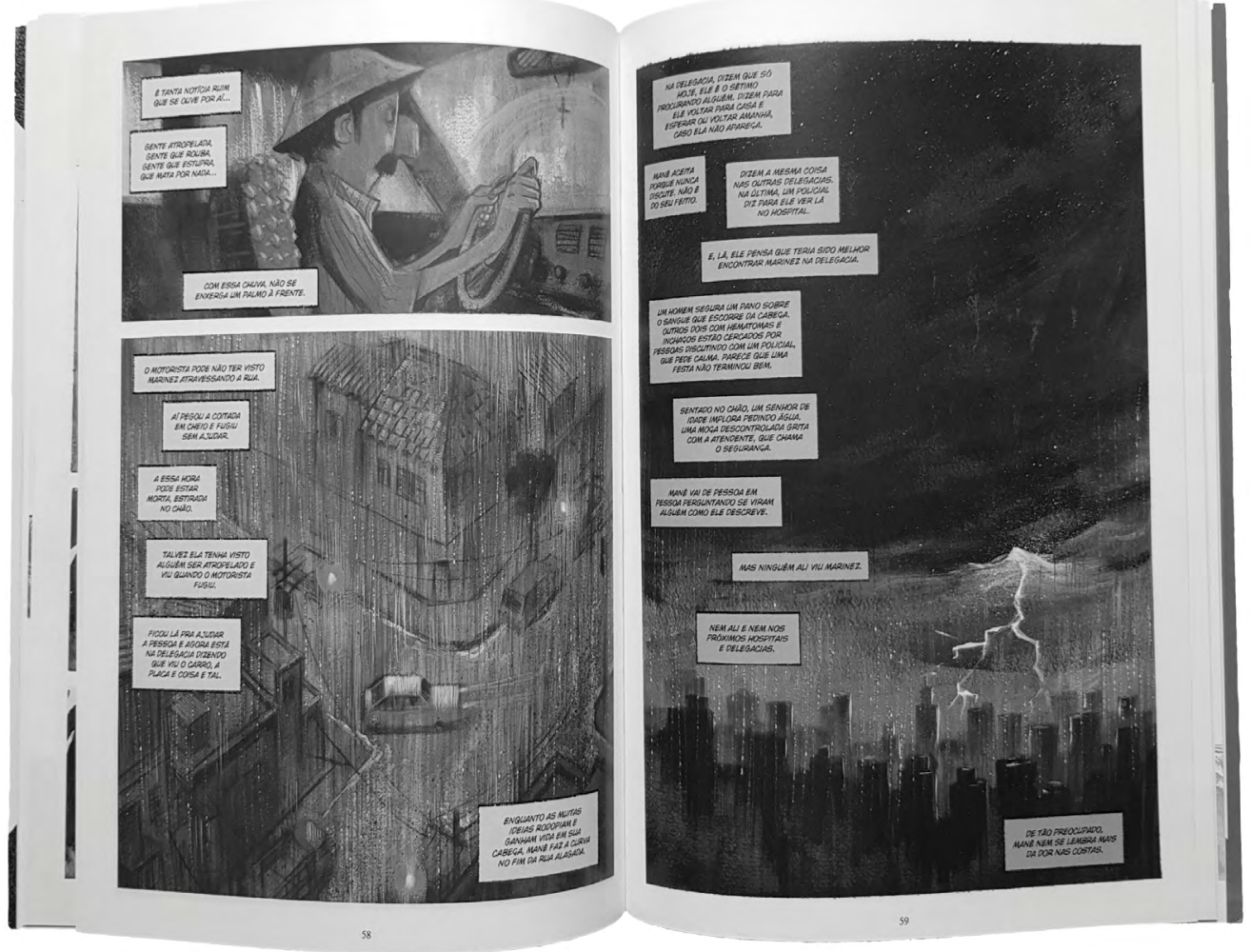


A narrativa em quadrinhos já é, por si só, uma construção intermidiática ao se utilizar do verbal, visual e gráfico em sua própria composição. Exige, portanto, uma leitura simultânea das diferentes linguagens pois, sem isso, não é possível a compreensão da obra como um todo, uma vez que os elementos estão interligados, complementando-se. As lacunas deixadas por uma linguagem são preenchidas pela outra e, assim, na simultaneidade da leitura, possibilita-se ao leitor compreender o que está sendo narrado de forma holística.

O livro, conforme aponta a leitura, é uma homenagem à obra de Adoniran Barbosa, mas é também a possibilidade visual das músicas que marcaram uma geração e que correspondem tanto à cidade de São Paulo, um samba gráfico que cria um diálogo entre a literatura e a música, incorporando visualmente elementos de uma mídia auditiva.

\section{CONCLUSÃO}

A leitura empreendida permite-nos observar que, em ambos os livros, a linguagem da música é incorporada na obra literária, por meio do texto verbal, narrativa visual e projeto gráfico, ou seja, em razão de suas composições intermídia. A relação, entretanto, é tecida de forma distinta em cada uma das obras, demonstrando, assim, que o diálogo entre mídias pode se dar em diferentes graus e de modos diversos. 
Em $O$ Rei, os autores se utilizam principalmente do projeto gráfico e das ilustrações para criar um diálogo com a linguagem musical, explorando os recursos táteis e visuais para expandir a construção de significados veiculados pela letra da canção de Tatit. Na questão tátil, é empregado um formato diferenciado para remeter a um disco com o qual o leitor deve interagir para acessar a obra, retirando o livro da luva que sugere a aproximação da capa de um LP. A narrativa visual, por sua vez, se utiliza do aspecto visível da própria música - as partituras e as notas - para a composição das imagens. Por meio de técnicas mistas que envolvem colagens, sprays e tintas, a obra traz um uso não literal das partituras e notas musicais, utilizando-as em diferentes contextos; além disso, o elemento Sol, personagem principal, é representado, por vezes, de forma humanizada, outras vezes apenas pela presença da cor amarela. Todos os signos, táteis ou visuais, que se referem à algum aspecto musical estão em diálogo direto com a origem do texto verbal desta obra, a letra de uma canção de Luiz Tatit.

Quaisqualigundum, porsuavez, enfatiza a relaçãoliteratura e música por meio da linguagem verbal, estabelecendo diálogos intertextuais com a obra de Adoniran Barbosa. A obra explora com profundidade as particularidades das 
canções do compositor paulistano, tais como o regionalismo e o emprego da linguagem coloquial. As falas dos personagens de Quaisqualigundum (2014) são escritas como são faladas, incorretas do ponto de vista gramatical, mas decisivas para o enriquecimento do contexto apresentado, conferindo a eles mais personalidade. Alusões às canções de Adoniran também reforçam o diálogo entre as mídias, de modo que grandes clássicos do músico, como Trem das Onze e Tiro ao Álvaro, que não são têm em um capítulo exclusivo a elas dedicado, são lembradas em diversas cenas, por meio da presença de personagens as cantarolando, revelando-se como músicas que estão em seus repertórios, assim como no nosso enquanto leitores. Em outras palavras, a relação ficção e realidade é estreitada também através da intermidialidade entre a literatura e a música.

O Rei e Quaisqualigundum apresentam-se, desta forma, como obras que travam diferentes diálogos com a música, os quais são tornados possíveis em virtude da composição híbrida - verbal, visual e gráfica - que revelam. Diálogos que demandam uma nova forma de leitura: a leitura sinérgica das diferentes camadas de linguagens que constituem a obra literária juvenil contemporânea. Uma literatura sonora, graficamente melódica e capaz, certamente, de despertar o interesse do jovem leitor. 


\section{REFERÊNCIAS}

BARBOSA, Adoniran (1974a). "Apaga o fogo mané". Adoniran Barbosa. São Paulo: EMI.

(1974b). "Saudosa Maloca". Adoniran Barbosa. São Paulo: EMI. (1975). "Samba do Arnesto". Adoniran Barbosa. São Paulo: EMI. (2013). "Samba no Bixiga". Adoniran Barbosa ao Vivo. São Paulo: Kuarup Music.

CLÜVER, Claus (2006a). "Da transposição intersemiótica". In: ARBEX, Márcia. Poéticas do visível: ensaios sobre a escrita e a imagem. Belo Horizonte: Editora da UFMG. (2006b). "Inter Textus/Inter Artes/Inter Media”. Aletria, 14, Jul-

Dez. In http://www.periodicos.letras.ufmg.br/index.php/aletria/article/ view/1357 Acesso em 17.Nov.2019.

CRUZ, Roger; CALIL, Davi (2014). Quaisqualigundum. São Paulo: Dead Hamster.

GENETTE, Gerard (2006). Palimpsestos: A literatura de segunda mão. Luciene Guimarães e Maria Antônia Ramos Coutinho (Trads.). Belo Horizonte: Faculdade de Letras.

HASSET, Dawnene; CURWOOD, Jen Scott (2009). "Theories and practices of multimodal education". The Reading teacher, 63(4), 270-282.

JUNIOR, Aldaci (2014). "Quaisqualigundum". Universo HQ. In www. universohq.com/reviews/quaisqualigundum Acesso em 17.Nov.2019.

TATIT, Luiz (1997). “O Rei”. Felicidade. São Paulo, Dabliu. ; MORICONI, Renato (2015). O Rei. São Paulo: Jujuba.

Diana Navas é pós-Doutora pela Universidade de Aveiro; Doutora em Literatura Portuguesa pela Universidade de São Paulo (USP) e Mestre pela Pontifícia Universidade Católica de São Paulo (PUC-SP). Atua como professora na PUC-SP no Programa de Estudos Pós-Graduados em Literatura e Crítica da PUC-SP. Suas pesquisas recentes concentram-se nas tendências da literatura juvenil contemporânea brasileira e portuguesa, e 
na materialidade do livro juvenil. Dentre suas publicações, destacam-se: Literatura Juvenil dos dois lados do Atlântico (2016); e a organização de $A$ literatura infantil e juvenil na contemporaneidade: histórias, caminhos e representações (2016); e Literatura \& Ensino: territórios em diálogo (2018). Integra os grupos de pesquisa Crítica Literária: tendências e perspectivas da PUC-SP; e A Narrativa Ficcional para Crianças e Jovens: teorias e práticas, da UERJ. É também membro do Grupo de Trabalho Literatura Infantil e Juvenil da ANPOLL.

E-mail: diana.navas@hotmail.com

ORCID iD: https://orcid.org/0000-0002-5307-8325

Luara Almeida é Mestranda (bolsista CAPES) em Literatura e Crítica Literária pela Pontifícia Universidade Católica de São Paulo (PUC-SP) e pósGraduada em Direção de Arte em Comunicação pelo Centro Universitário Belas Artes de São Paulo. Participa dos grupos de pesquisa A voz escrita infantil e juvenil: práticas discursivas e $O$ narrador e as fronteiras do relato da PUC-SP.

E-mail: luaraalmeida13@hotmail.com

ORCID iD: https://orcid.org/0000-0002-4516-5832 